\title{
Analysis of the Volume of Air Cargo Traffic in Major International Airports in Nigeria
}

\author{
Adenigbo, Joseph Adedotun*, Ubogu, Andrew Egba \\ Department of Transport Management TechnologyFederal University of Technology, Akure, Ondo State, \\ Nigeria \\ Department of Geography \& Regional Planning Federal University, Dutsin-ma, Katsina State, Nigeria
}

\begin{abstract}
This paper analyzes the volume of air cargo handled at the major international airports in Nigeria. The study used both primary and secondary sources of data collection. The primary source of data collection made use of 369 copies of questionnaire administered by simple random method to agents who are physically located at the premises of the airports in order to determine cargo types and the cargo that dominates flows at the airports. Mainly, the secondary data for the study was the extraction of the volume of cargo flow from 2006 - 2011 at the airports from the records of Nigerian Aviation Handling Company (NAHCo), headquarters. The study employed Location Quotient (LQ) and Specialisation Index (SI) to determine the airports' share and specialisation in the handling and flow of cargo in Nigeria. The results show that electronics and computers dominate flows in Lagos, machine parts in Abuja and Port-Harcourt, and textiles in Kano airports. It also revealed that Lagos airport handled its proportionate share of cargo traffic for the years under consideration except in 2007 and 2010 with $L Q=0.9$ respectively. Port-Harcourt airport handled less of its share of cargo traffic for 3 years consecutively with very low LQ of 0.4, 0.6, and 0.5 in 2007, 2008 and 2009 respectively. Also, the study observed that all the airports are specialised in handling dominant cargo type. The study recommends that the air cargo industry need to be structured such that it will enhance increase flow of different cargoes at various airports in Nigeria to ensure maximum capacity utilisation of the airports.
\end{abstract}

Keywords: Air Cargo; Flow; Location Quotient; Specialisation Index; Airport Share; Cargo Type

\section{Introduction}

Air cargo transportation system is designed to provide fast and efficient shipment of goods. Fast and efficient because it is the fastest mode of transport and it is used safely to carry high valued goods. The meaning of air cargo in this work takes the definition provided by the International Air Transport Association (IATA) as being the equivalent of goods, meaning any property carried or to be carried on an aircraft except mail or other property carried under terms of an international postal convention, or baggage carried under a passenger ticket and baggage check, but baggage moving under an airway bill or shipment record.

The proper functioning of air cargo transport affects the economic viability not only of the aviation industry, but also of the national and international high-value, just-in-time (JIT) supply chain that serves many other manufacturing, service and trading industries. The concept of JIT covers manufacturing and distribution system that relies on meeting immediate needs, as opposed to carrying large inventories "just-in-case" (Boeing, 2005). In the new fast-cycle logistics era, air cargo enables businesses, regardless of their location, to connect distant markets and global supply chains in an efficient, expeditious, and reliable manner (Kasarda and Sullivan, 2006). The emergence of globally integrated JIT production and distribution systems and the emergence of ecommerce and e-business have made air cargo the fastest growth area in the cargo sector (Hui et al 2004). However, Hsu et al (2005) argued that the way to deliver high-tech products by liner shipping is less efficient than by airline and it shows the importance of air cargo.

Due to increased market demand, Buzdugan (2005) asserts that the volume of cargo transported by air grew significantly, and it is expected to continue to increase at a pace that will surpass the future growth of passenger air travel the world over. Simply put, transport of goods by air has become an essential component of contemporary economy. Karsada and Sullivan (2005) quoting World Cargo Traffic Model (2003) argued that the huge volume of high-value, time-critical products traversing international boundaries by air annually has resulted in air cargo accounting for approximately 40 percent of the value of today's world trade.

Air cargo is not just a facilitator; it is a trade creator that contributes to the competitive advantages of nations through established strong relationship that exists between levels of air cargo volume and both Gross Domestic Product (GDP) and GDP per capital (Kasarda and Green 2004). Air cargo service has been a tremendous enabler to economic development. This is because air freight and integrated air express are critical to time-based competition - the frontier challenge for the world's most-advanced firms. Air cargo has also facilitated specialization and allowed the well-developed countries - their producers and consumers to reap the 
benefits of ever-closer matches between demands and supply (Jiang et al, 2006). This is due not just to the speed of air transport but to the geographical reach it allows which enlarges effective market areas to the point that increasingly small product niches reach the threshold of feasible production (Karsada et al 2006).

Air cargo flow seems to be characterized by constraints in Nigeria which depicts a symptom of poor co-ordination of cargo for efficient distribution and supply chain that is not cost-effective. Efficient distribution requires safe and timely means of transporting specialized cargo with high value to volume/weight ratio. These constraints according to Afolabi (2005a) revealed that the warehouses and facilities in Nigeria airports were not adequate enough to handle the volume of air cargo for efficient flow. The author further identified tough clearing procedure as a constraint to the air cargo industry in Nigeria.

Moreover, Afolabi (2005b) highlighted the issue of protection and security of air cargo, improper declaration and documentation of goods in terms of types and volume as constraints to air cargo flow in Nigeria. These therefore results in an airport handling cargo type whose origin or final destination is not close to the airport at the expense of other airports with relative closeness. This serves as productive set back to Nigeria in the sense that firms/industries that require high-value fast moving materials would not thrive while the air cargo industry will not grow to be able to compete in global supply chain and distribution. This is because most of these cargoes are important in production processes since they serve as raw materials and/or equipment required for service delivery.

A review of the studies in Nigerian air transport reveals that not much attention had been accorded to the flow of air cargo, while deliberate attention had been given to the analysis of the flow of passenger, aircraft movement, flight operations emphasising safety and security, as well as issues on policy and bilateral agreements. Such studies include that of Ayakpat (2010) on the effects of liberalisation and open skies agreement on Nigeria airlines passenger operations in Nnamdi Azikwe international airport, Abuja using descriptive analysis of data, and found that the policy of Open Skies Agreement has not decreased the foreign airline earnings but rather increased its revenue over domestic airlines in Nigeria.

In the same vein, Idrisu (2004) worked on the commercial and regulatory implications for air transport liberalization and open skies agreement in Nigeria while Gambiye (2010) carried out an assessment of the ticketing and reservation operations of IRS Airline in Yola; Oladele (2005) assessed the African air transport in the 21 st Century by contrasting Nigeria and Kenya's experiences; and Yahaya (2005) carried out an assessment on the airport capacity utilization in Nigeria.

However, related works on air cargo carried out in Nigeria are in different dimensions and not as intensive compared to what has been done in other countries. Aderamo (2010) assessed the demand for air transport in Nigeria and factors responsible for it. The author looked at passenger, aircraft and freight traffic, and the relative demand for them in the country. The results show that the index of manufacturing production, inflationary rate, Gross Domestic Products (GDP), Federal government expenditure in current prices, and consumer price are important explanatory variables of the demand for air transport in Nigeria. Specific works on air cargo in Nigeria are that of Afolabi (2005a) on the bane of air cargo development in Nigeria, which highlighted the problem of warehouses in air cargo handling, and suggested that it is the prerogative of the Federal Airport Authority of Nigeria (FAAN) to provide and build warehouses that can house different kinds of goods. Similarly, Olateru's (2005) study on the importance of air cargo business to the economy of Nigeria revealed that most airlines relied so much on cargo business for revenue generation even though they were not dedicated cargo airlines. Furthermore, the study asserts that cargo business is a 40 billion-dollar business which the airlines and government can make a lot of money from, and recommended that the government should close the gap between the volume of import and export of air cargo in the country.

This dearth of empirical studies relating to the nature of air cargo flow in Nigeria is as a result of underdevelopment of supply chain management in the air cargo industry. According to Ayodele (2010) facts and figures on cargo movement in and out of Nigerian airports show that cargo transportation can contribute significantly to Nigeria's GDP, if properly developed. The author further stressed that air cargo is the most vital and lucrative aspect of air transportation, yet the most neglected. However, in other countries, there are compact body of researches in related areas that identify common themes and provide the basis on which to develop empirical research for this study. Examples of such works include Zhang (2003); Hui et al (2004); Gardiner et al (2005) and Kasarda et al (2006).

This study therefore seeks to analyse the volume of cargo flow in Nigeria's major international airports with a view to determining airport's cargo handling share and specialization, and compare the airports' specialised handling of cargo in Nigeria.

\section{Materials and Methods}

This study used data collected on the types and volume of air cargo traffic at the major international airports of Nigeria. The primary source of data collection to determine the types of cargo flow at the airports made use of structured questionnaires administered to cargo agents while the secondary data was sourced from 
the records of Nigeria Aviation Handling Company (NAHCo) on the volume of air cargo handled at the airports from $2006-2011$.

Cargo handling sector of Nigeria is structured such that it has successfully seen private firms involved much more in cargo handling other than the government that was bedevilled with mal-administration. This structure has ensured two major cargo handlers in Nigeria with NAHCo fully privatised while Skypower Aviation Handling Company Limited (SAHCOL) a subsidiary of the liquidated Nigeria Airways was completely sold out to private operator and started operations in 2010. Consequently, NAHCo established in 1979 still dominate cargo handling market in Nigeria with larger percentage of airline patronage while handling over $70 \%$ of cargo volume in Nigeria. In consideration of this, the study limited its data to the records of NAHCo at the four major international airports in Nigeria.

The sample size of cargo agents for the study was determined using a formula developed by Yamane (1967) for determining sample size where a population is known. The study therefore sampled a total of 392 of the 18,780 NAHCo registered agents in 2010. The Yamane (1967) formula for the determination of sample size is as follows;

Where,

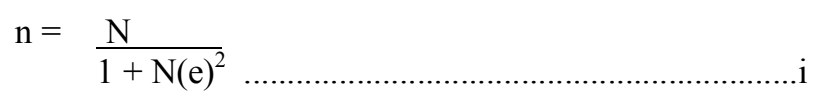

$\mathrm{n}=$ Sample size;

$\mathrm{N}=$ Population size; and

$\mathrm{e}=$ level of significance (set at 0.05 for this study)

Hence,

$$
\begin{aligned}
& \mathrm{n}=\quad 18780 \\
& 1+18780(.05)^{2} \\
& =392
\end{aligned}
$$

The proportionate distribution of the total sample size by airports is presented in Table 1 .

Where,

\begin{tabular}{|c|c|c|c|}
\hline Airports & 2011 Registered Cargo Agents & Sample Size & No of Sample Used \\
\hline Lagos & 10,414 & 217 & 203 \\
\hline Abuja & 5,883 & 123 & 116 \\
\hline Kano & 1,486 & 31 & 28 \\
\hline Port Harcourt & 997 & 21 & 22 \\
\hline Total & 18,780 & 392 & 369 \\
\hline
\end{tabular}

Sample size per airport $=\quad$ Airport Population $\times$ Total Sample size

Total Population

Table 1: Distribution of Questionnaires

Source: Extracted from NAHCo 2011

A total of 369 copies of the questionnaire, representing $94 \%$ success rate were completed and returned, which elicits information on the types of cargo and dominant cargo type at each of the airports. Some of the remaining $6 \%$ were not returned, some were not correctly filled while a few others were returned blank. The study adopts simple random method for the administration of the questionnaires among cargo agents in order to identify a cargo type that dominates traffic flow in these airports. The need to use primary method of data collection to determine cargo types and the dominant cargo type at the airports arises because NAHCo records of cargo volume handled at the airports are not disaggregated based of the types of cargo. Therefore the study made use of the 369 copies of the completed questionnaire as sample size. The study conducted in-depth interviews with the staff of NAHCo in cargo sheds to identify the types of cargoes that are handled at the airports.

Apart from the descriptive statistics of data analysis, the study employed Location Quotient (LQ) analysis to determine the share of each airport in the handling of cargo, and Specialisation Index (SI) to determine the level at which each airport is specialised in cargo handling because of the non disaggregated nature of cargo records of NAHCo by types and volume of cargo. The Location Quotient (LQ) model is applied here to determine the share of traffic handled at an airport in a particular period of time. It is calculated using;

$\mathbf{L}_{\mathbf{i}} \mathbf{K}=\left(\mathbf{X}_{\mathbf{i}} \mathbf{K} / \mathbf{X K}\right) /\left(\mathbf{X}_{\mathbf{i}} / \mathbf{X} ..\right)$. .. i

Where, $\mathrm{L}_{\mathrm{i}} \mathrm{K}$ represent Location Quotient;

$\mathrm{X}_{\mathrm{i}} \mathrm{K}=$ volume of cargo at an airport in a particular year;

$\mathrm{XK}=$ total volume of cargo at all the airports in a particular year;

$\mathrm{X}_{\mathrm{i}}=$ total volume of cargo at a particular airport for all the years; and 
$\mathrm{X} . .=$ total volume of cargo for all the airports over the period of years.

The greater the value of the index, the greater is the degree of an airport's share of cargo. There are three possible outcome of location quotient. The first type is an index lower than 1 which indicates that the share of cargo in an airport is under-represented. The second type is an index that is equal to 1 . This indicates that the volume of cargo share in an airport is proportional to its participation of total distribution in air cargo traffic. Finally, an index above 1 indicates that the cargo volume of an airport is preponderant to the total cargo distribution of the airports.

The analysis of the specialisation index in this study is modified from (Comtois, 2013) in order to achieve its purpose of determining the specialisation of airports in cargo traffic over a period of time rather than focussing on cargo type specialisation at airports. Therefore, the Specialisation Index is calculated using this formula;

$$
\begin{aligned}
& \mathbf{S I}=1 / 2 \quad\left(\mathbf{X}_{\mathbf{i}} \mathbf{K} / \mathbf{X}_{\mathbf{j}} \mathrm{K}\right)-(\mathbf{X} / \mathbf{X} . .) \quad \text {......................................................... ii } \\
& \text { Where, } \quad \mathrm{SI}=\text { Specialisation Index } \\
& \mathrm{X}_{\mathrm{i}} \mathrm{K}=\text { volume of cargo at an airport in a particular year }
\end{aligned}
$$

and

The index usually tends towards 1 or 0 . If the specialisation index tends towards 1 , it means the airport is diversified in cargo traffic, but if it tends towards 0 , it means the airport is specialised in cargo handling. The modification and application of these index models in this study is because of their versatility in that they can be used for different types of data involving regions or locations.

The study covers the four major international airports in Nigeria as the study area. The airports are Muritala International Airport (Lagos Airport), located in the Southwest of Nigeria, Nnamdi Azikwe International airport (Abuja Airport), located in the North central of Nigeria, Mallam Aminu Kano International Airport (Kano Airport) located in the Northwest of Nigeria, and Port-Harcourt International Airport (PortHarcourt Airport) located in the South-South region of the country. These airports are the dominant airports in the handling of both domestic and international flights of passengers and cargoes in Nigeria. Other named international airports in Nigeria mostly operate seasonally, especially during pilgrimages.

\section{Results and Discussion}

In analyzing the volume of cargo traffic, there is need for the identification of cargo types that are handled at the airports. This study identifies the types of cargo that flow at the airports and also the specific cargo type that dominates traffic flow at each of the airports. The cargo type dominating traffic flow at the airports in the study is the one the cargo agents (respondents) identified as the most frequently handled at each of the airports.

Table 2 shows a total of eleven (11) different types of cargoes that are handled at the four major international airports in Nigeria, and classified as high valued goods and time sensitive goods similar to the classification of Carolina (2005) in reference to Radnoti (2002).

Table 2: Types of Air Cargo Flowing at Nigeria's major International Airports

\begin{tabular}{ll}
\hline High Valued Goods & Time Sensitive Goods \\
\hline Electronics/Computers and Accessories & Perishables \\
Cameras/Photographic Equipment & Live Animals \\
Textiles & Food Products \\
Medical Equipment & Emergency goods. \\
Chemicals & \\
Pharmaceuticals & \\
Machine Parts & \\
\hline
\end{tabular}

Source: Field Survey, 2012.

High valued goods are goods that require special handling because of its high financial worth and usefulness. These types of goods might be small or moderate in size but worth far more than its physical characteristic. On the other hand, time-sensitive goods are goods requiring immediate supply and delivery to the final leg of the supply chain. These goods are majorly meant to be supplied within a limited period of time. They are goods that are susceptible to destruction in their natural conditions within a limited period of time. Examples include flowers, fruits, and vegetables. Conversely, high valued goods that require urgent delivery based on a special request for the delivery of the good. The high valued goods that may be time sensitive include drugs, medical devices and machine parts. 
Table 3: Dominant Cargo Flow in Nigeria's International Airports

\begin{tabular}{|c|c|c|c|c|c|c|c|c|}
\hline \multirow{3}{*}{ Cargo Types } & \multicolumn{8}{|c|}{ Airports } \\
\hline & \multicolumn{2}{|c|}{ Lagos } & \multicolumn{2}{|c|}{ Abuja } & \multicolumn{2}{|c|}{ Kano } & \multicolumn{2}{|c|}{ Port-Harcourt } \\
\hline & $\mathrm{N}$ & $\%$ & $\mathrm{~N}$ & $\%$ & $\mathrm{~N}$ & $\%$ & $\mathrm{~N}$ & $\%$ \\
\hline Electronics/Computers & 124 & 61 & 3 & 2.6 & 3 & 10.7 & - & - \\
\hline Medical Devices & 10 & 4 & - & - & - & - & - & - \\
\hline Textiles & 25 & 12.2 & - & - & 14 & 50 & - & - \\
\hline Machine Parts & 32 & 16 & 50 & 43.1 & 7 & 25 & 13 & 59.1 \\
\hline Perishables & 10 & 4.9 & 5 & 4.3 & 1 & 3.6 & - & - \\
\hline Live Animals & 2 & 1 & - & - & - & - & - & - \\
\hline Chemicals & - & - & 1 & 0.9 & 3 & 10.7 & - & - \\
\hline Emergency Goods & - & - & 1 & 0.9 & - & - & - & - \\
\hline Pharmaceuticals & - & - & 42 & 36.2 & - & - & 3 & 13.6 \\
\hline Others $^{1,2}$ & - & & 14 & 12 & - & - & 6 & 27.3 \\
\hline Total & 203 & 100 & 116 & 100 & 28 & 100 & 22 & 100 \\
\hline
\end{tabular}

${ }^{1}$ Diplomatic goods; ${ }^{2}$ Oil-Well Equipment

Source: Field Survey, 2012

The study shows that electronics and computers dominate the flow of air cargo in Lagos airport with $61 \%$ of the total respondents at the airport. This indicates that the rate at which electronics and computers flow at the airport is very high compared to other cargo types like machine parts, textiles and perishable goods. Most of these electronics and computers are imported into the country by individuals who travel to other countries, or sent to person(s) whose relatives/friends are based in the foreign countries. In fact, it is instructive to note that most of these computers and electronics end up in the computer market in Lagos, which is the single largest market of its kind in Nigeria. This indicates that most of the computers shipped by air to Nigeria through Lagos airport are meant for trade in the computer market located very close the airport.

Unlike the Lagos airport, machine parts dominate flows at the Nnamdi Azikwe International Airport, Abuja. Majority of the respondents representing $43.1 \%$ of the cargo agents at the airport identified machine parts as the dominant cargo type flowing at the airport, and followed by pharmaceuticals with $36.2 \%$ of the total respondents. "Others" such as diplomatic goods accounted for $12 \%$ of the total cargo handled at the airport. Indeed, the importation of machine parts through the Abuja airport can be partially attributed to the presence of construction companies such as Julius Berger, Dantata \& Sawoe and others in the city. These construction companies need machine parts as part of their logistics requirements because of the abundance of ongoing construction projects in the Federal Capital Territory (FCT). Similarly, many Non Governmental Organisations (NGOs) and other world governing organisations like World Health Organisation (WHO), United Nations (UN) and United Nations Children Education Fund (UNICEF) bring different kinds of pharmaceuticals in form of drugs into the country on a regular basis. Diplomatic goods (represented by others) meant for use at the various embassies in Nigeria also flows into the country through Abuja airport in a significant volume as a result of the seat of government in Abuja.

Similarly, Table 3 shows that textiles (with $50 \%$ ) dominate the flow of cargo at the Mallam Aminu Kano International Airport (MAKIA), Kano. This implies that Kano serves as the largest textiles market in Nigeria, where textiles materials are much available and cheaper than any other parts of the country. The $25 \%$ responses for machine parts and a cumulative $20.4 \%$ for electronics/computers and chemicals can be associated with the presence of branch offices of manufacturing companies in Kano coupled with the individual's increased demand for computers in Nigeria. This is because of the large market size in Kano as a result of high population density.

As regard the dominant cargo type in Port-Harcourt airport, machine parts forms the single most dominant cargo that is handled at the airport. This accounted for $59.1 \%$ of the total response of cargo agents at the airport. This is because spare parts are needed by the oil and gas companies in the region. Oil well equipments (represented by others) are meant for use at the various oil-well sites in the area. The prominence of pharmaceuticals at the airport with $27.3 \%$ response can be partially attributed to the effect of oil exploration on the environment requiring the people to take some drugs to cushion the negative environmental impact on their health.

It can be summarised here that electronics/computers dominate flows in Lagos, machine parts dominates cargo flow in Abuja and Port-Harcourt, while textiles dominate in Kano. In addition, diplomatic goods are common in Abuja airport, while oil well equipment flows into Port-Harcourt airport.

\subsection{Volume of Cargo Flow at Major International Airports in Nigeria}

Cargo flow is the life blood of aviation market because high valued and time sensitive goods are mostly transported using air transport system. Cargo traffic has become stable source of increased revenue for airlines; 
as a result of which airlines carry cargo in the belly of their passenger aircrafts apart from the dedicated cargo aircrafts.

In transport, the nature of flow is directional for cargo, passenger or vehicle traffic. This can be inflow or outflow. The inflow is the movement that originates from an external location but destined to a specific region. The outflow is the movement from and within a location and destined for a new location. Hence, Table 4 presents the volume of air cargo flow at Nigeria's major international airports by specifying both inflow and outflow volume.

The total volume of inflow cargo across the airports was 86,796,322 tonnes in 2006; it increased to $120,687,240$ tonnes in 2009 . However, the total inflow of cargo volume drastically reduced to $57,088,103$ tonnes in 2010 and by 2011 it increased to $83,606,579$ tonnes. The trend across the airports in the volume of inflow cargo shows fluctuations over the years under consideration.

Similarly, the trend of outflow cargo volume of the airports shows a pattern of increase and decrease. The total outflow cargo volume stood at 31,798454 tonnes in 2006, and decreased from 30,420,862 tonnes in 2007 to $27,455,266$ tonnes by 2008 . However, it increased to $32,875,563$ tonnes in 2009 and by 2011 it has decreased significantly to $11,584,221$ tonnes (See Table 4). The decline in outbound cargo traffic as compared to inbound cargo volume implies that the country is import dependent.

Table 4: Volume of Air Cargo Flow at International Airports in Nigeria from 2006 - 2011 (in '000 Tonnes)

\begin{tabular}{|l|l|l|l|l|l|l|l|l|l|l|l|l|l|}
\hline \multirow{2}{*}{$\begin{array}{l}\mathbf{2 0 0 6} \\
\text { Airports }\end{array}$} & Inflow & Outflow & Inflow & Outflow & Inflow & Outflow & Inflow & Outflow & Inflow & Outflow & Inflow & Outflow \\
\hline Lagos & 80,744 & 30,551 & 95,762 & 28,881 & 90,630 & 26,238 & 114,528 & 31,108 & 49,900 & 17,992 & 75,939 & 10,170 \\
\hline Abuja & 1,602 & 235 & 2,542 & 383 & 3,284 & 409 & 3,238 & 345 & 3,114 & 416 & 2,257 & 310 \\
\hline Kano & 772 & 1,011 & 1,898 & 1,155 & 1,616 & 807 & 1,127 & 1,422 & 891 & 1,160 & 1,005 & 1,103 \\
\hline $\begin{array}{l}\text { Port- } \\
\text { Harcourt }\end{array}$ & 3,676 & - & 1,216 & - & 1,559 & - & 1,792 & - & 3,181 & - & 4,404 & - & \\
\hline Total & $\mathbf{8 6 , 7 9 4}$ & $\mathbf{3 1 , 7 9 7}$ & $\mathbf{1 0 1 , 4 1 8}$ & $\mathbf{3 0 , 4 1 9}$ & $\mathbf{9 7 , 0 8 9}$ & $\mathbf{2 7 , 4 5 4}$ & $\mathbf{1 2 0 , 6 8 5}$ & $\mathbf{3 2 , 8 7 5}$ & $\mathbf{5 7 , 0 8 6}$ & $\mathbf{1 9 , 5 6 8}$ & $\mathbf{8 3 , 6 0 5}$ & $\mathbf{1 1 , 5 8 3}$ \\
\hline
\end{tabular}

Source: NAHCo Annual Reports 2006 - 2011

\subsection{Airport's Share of Cargo handling in Nigeria}

The volume of cargo handled across the airports reveals that cargo traffic stood at 118,594,776 tonnes in 2006 and it increased to $153,562,803$ tonnes in 2009 . However by 2011 , cargo traffic decreased to $95,190,800$ tonnes. Similarly, the trend across the airports shows fluctuations in the total volume of cargo handled on yearly basis (See Table 5). It also revealed that Lagos airport alone handled $93.1 \%$ of the total cargo volume of the airports from $2006-2011$.

Table 5: Total Volume of Cargo Flow at Nigeria International Airports 2006 - 2011

\begin{tabular}{|c|c|c|c|c|c|c|c|}
\hline \multirow[b]{2}{*}{ Airports } & \multicolumn{5}{|c|}{ Year } & \multirow[b]{2}{*}{2011} & \multirow[b]{2}{*}{ Total } \\
\hline & 2006 & 2007 & 2008 & 2009 & 2010 & & \\
\hline Lagos & $111,296,581$ & $124,644,070$ & $116,869,050$ & $145,636,830$ & $67,893,059$ & $86,109,848$ & $652,449,438$ \\
\hline Abuja & $1,838,048$ & $2,926,044$ & $3,694,856$ & $3,583,536$ & $3,531,142$ & $2,567,102$ & $18,140,728$ \\
\hline Kano & $1,784,088$ & $3,054,607$ & $2,423,954$ & $2,549,939$ & $2,052,111$ & $2,109,153$ & $13,973,852$ \\
\hline Port-Harcourt & $3,676,059$ & $1,216,120$ & $1,559,850$ & $1,792,498$ & $3,181,615$ & $4,404,697$ & $\mathbf{1 5 , 8 3 0 , 8 3 9}$ \\
\hline Total & $118,594,776$ & $131,840,841$ & $124,547,710$ & $153,562,803$ & $76,657,927$ & $95,190,800$ & $700,394,857$ \\
\hline
\end{tabular}

Source: NAHCo Annual Reports 2006 - 2011

The values in Table 6 is the results of the Location Quotient (LQ) analysis as calculated from Table 5 in order to determine the share of each airport in cargo handling on a yearly basis. The Table 6 shows that Lagos had less than its share of cargo handling in 2007 and 2010 with LQ $=0.9$ respectively. But this value is very much close to 1.0 which the airport had for the other 4 years. It implies that Lagos' share of cargo handling over the years has been commensurate with the capacity of the airport to handle cargo. This is because Lagos airport being the largest and busiest airport in Nigeria has remained the major airport for both passenger and cargo flights because of the high population density and business demand in Lagos.

The airport in Abuja handled less than its share in 2006 with LQ = 0.6, while that of 2007 and 2009 is closer to unity (Table 6). Abuja being the capital of Nigeria has a number of headquarters of embassies and federal government ministries, departments and agencies (MDAs) that are believed to be responsible for the demand for cargo that flows at the airport. Kano airport handled less than its share with $\mathrm{LQ}=0.8$ in 2006 and 2009. However, it had more than its share in three out of the six years under consideration. Also, Kano airport had a LQ $=1.0$ only in 2008. This implies that cargo share of the airport is not stable over the years under consideration. This may be attributed to variations that characterises market demand for goods. The influence of market demand on Kano airport cargo share is because of the high population density in Kano city and its adjoining cities in the northern part of the country. 


\begin{tabular}{llllllll}
\multicolumn{9}{c}{ Table 6: Location Quotient for Airports' Cargo Handling } \\
\hline Airports & $\mathbf{2 0 0 6}$ & $\mathbf{2 0 0 7}$ & $\mathbf{2 0 0 8}$ & $\mathbf{2 0 0 9}$ & $\mathbf{2 0 1 0}$ & $\mathbf{2 0 1 1}$ \\
\hline Lagos & 1.0 & 0.9 & 1.0 & 1.0 & 0.9 & 1.0 \\
\hline Abuja & 0.6 & 0.9 & 1.1 & 0.9 & 1.8 & 1.0 \\
\hline Kano & 0.8 & 1.2 & 1.0 & 0.8 & 1.3 & 1.1 \\
\hline Port-Harcourt & 1.4 & 0.4 & 0.6 & 0.5 & 1.8 & 2.0 \\
\hline
\end{tabular}

Source: Computed from Table 4.

In Port-Harcourt, LQ of 0.4, 0.6 and 0.5 consecutively in 2007, 2008 and 2009 respectively shows that the airport handled less than its share for 3 years out of the 6 years under consideration. This trend is attributable to the effects of militancy and kidnapping that erupted in the region and lasted till 2008 when the federal government initiated the amnesty programme. Also the effect of fire outbreak that led to the closure of the airport's runway in August 2006 seems responsible for the very low cargo share at the airport. That the airport handled far more than its share in 2010 and 2011 (LQ = 1.8 and 2.0 respectively) indicates the opening of the airport's runway after reconstruction. Another probable reason may be the cessation of militant operations as a result of the amnesty programme of the government.

\subsection{Specialisation of Cargo Handling at International Airports in Nigeria}

Specialisation co-efficient analysis adopted in this paper is with a view to determining the airports' specialisation in handling cargo traffic. The analysis involves a calculation of index using the total volume of cargo flow (See Table 4) at each of the airports for the period under consideration i.e 2006 - 2011.

\begin{tabular}{lllllll}
\multicolumn{7}{c}{ Table 7: Specialisation Index of the Airports' Cargo Handling } \\
\hline Airports & $\mathbf{2 0 0 6}$ & $\mathbf{2 0 0 7}$ & $\mathbf{2 0 0 8}$ & $\mathbf{2 0 0 9}$ & $\mathbf{2 0 1 0}$ & $\mathbf{2 0 1 1}$ \\
\hline Lagos & 0.0035 & 0.0069 & 0.0068 & 0.0084 & 0.0229 & 0.0134 \\
\hline Abuja & 0.0052 & 0.0019 & 0.0019 & 0.0013 & 0.0101 & 0.0005 \\
\hline Kano & 0.0025 & 0.0016 & 0.0002 & 0.0017 & 0.0034 & 0.0011 \\
\hline Port-Harcourt & 0.0042 & 0.0067 & 0.0050 & 0.0055 & 0.0095 & 0.0899 \\
\hline
\end{tabular}

Source: Computed from Table 4.

Table 7 shows that it is evident that airports in Nigeria are specialised in cargo handling between and within locations in the country. This is because the specialisation index calculated for each airport tends towards 0 , even for all the years under consideration. It can be established that the airports handle a large quantity of the cargo type that dominates its traffic. This condition of specialised handling and flow of cargo at airports may stand to inhibit the volume of cargo that flows in different zones where these airports are located.

A further examination of the results presented in Table 7 shows that Lagos airport handled more of its traffic dominating cargo type in 2008 and 2009 with SI $=0.0068$ and 0.0069 respectively. In 2011, Abuja handled more of its dominating cargo type with S.I $=0.0005$, Kano airport handled more of its traffic dominating cargo type in 2008 with S.I $=0.0002$ while Port-Harcourt handled more of its dominating cargo type in 2006 with S.I $=0.0042$. It then implies that the more S.I of an airport in a particular year tends towards 0 , the more the airport is specialised in the handling of its dominating cargo type.

\section{Policy Implications and Conclusion}

The government of Nigeria at present embarked on considerable efforts towards the development of aviation industry. These efforts majorly geared towards safety and infrastructure development with a focus on cargo terminals infrastructure at the airports. It is hoped that this will consequently lead to increased cargo traffic at the airports, because airlines with cargoes destined to other neighbouring countries may decide to use the handling infrastructure in Nigeria airports, thereby increasing the volume of cargo traffic at the airports. The fact that Lagos airport maintain a dominance in the volume of cargo traffic over other airports because of the economic and industrial dominance of Lagos market should inform policy makers to develop a strategy by creating incentives in other airports to attract cargo agents to ship goods through the airports, thereby increasing the volume of cargo traffic flow at the airports.

The flow of a dominant cargo type at the airports is an indication of the influence of economic resource that dominates the region where the airports are located. This will probably serves as comparative advantage for the airports. This indicates the need to develop a policy that will encourage optimum maximisation of the advantage and at the same time, put pragmatic efforts in place to see to the need for increased flow of other types of cargo at the airports in order to reduce the rate of handling more of a cargo type.

The present structure of air cargo industry in Nigeria is a welcome development. This structure has successfully seen that private firms are much more involved in cargo handling other than the government that was bedevilled by mal operations. This structure has ensured two major cargo handlers in Nigeria with NAHCo fully privatised while SAHCOL a subsidiary of the liquidated Nigeria Airways was completely sold out to 
private operator. But these firms need to do an adequate documentation of cargo handled. NAHCo should endeavour to have record of cargo handled specified by type and volume while SAHCOL who started operations not long ago should make this a target.

The present condition of airports in Nigeria being import dominated can be traced to the remote causes that have encouraged decline outbound cargo traffic arising from poor supply chain management and logistics of goods distribution coupled with the fact that the country's manufacturing and production industry suffers from the menace underdevelopment.

In conclusion, the global trend of the increasing demand for air cargo and the consequent need of airport service for cargo handling place a requirement on the airports' ability to handle various cargo types even if the final destination of the cargo is not close to the location of the airport. Major new trends in global air cargo market can be summarized as forming strategic alliances in air cargo field among air carriers, developing information technology, and emerging integrators. In Nigeria, air cargo volume will be increased rapidly with the growth of the country's economy. But if the four major international airports in the country are provided with adequate and equal facilities geared towards quality service delivery to enhance increased cargo share and diversified cargo type handling, fierce competition among airports will be deployed to attract air cargo of the West Africa region.

\section{Acknowledgement}

The authors are very grateful to Mr Adebiyi of Corporate Communications Department of the NAHCo headquarters, Lagos who willingly provided the data required for this paper.

\section{References}

[1]. Aderamo, J.A. (2010). Demand for Air Transport in Nigeria. Journal of Economics, vol. 123 - 31

[2]. Afolabi, C. (2005a). Bane of Air Cargo Development in Nigeria. Paper presented at the first yearly cargo conference organized by Aviation Review, Lagos, from http://news.biafranigeriaworld.com/achive/guardian/2005/12/27. Accessed 8/7/2011

[3]. Afolabi, O. (2005b). Air Cargo: Tool for Economic Development. Keynote Address at the first yearly cargo conference organized by Aviation Review, Lagos, from http:news.biafranigeriaworld.com/achive/guardian/2005/12/27.Accessed $\underline{8 / 7 / 2011}$

[4]. $\quad$ Ayakpat S. (2010). The Effects of Liberalisation and Open Skies Agreement on Nigeria

[5]. Airlines Passenger Operations in Nnamdi Azikwe International Airport, Abuja. Unpublished PGD Research study at the Nigerian Institute of Transport Technology (NITT), Zaria.

[6]. Ayodele, S (2010). Why world mega Cargo carriers avoid Nigeria's Air Transport market. Report in the Business Day Newspaper on Thursday, 30 December 2010.

[7]. Boeing, (2005). World Air Cargo Forecast (WACF 2004/2005). Online: http://www.boeing.com/commercial/cargo/WACF 20042005. Accessed 1/3/2011.

[8]. Buzdugan, M. (2005). Current and Emerging Air Cargo Security and Facilitation Issues. Institute of Air and Space Law, McGill University, Montreal.

[9]. Comtois Claude (2013). The Specialization Index and the Location Coefficient. Available on The internet: http://people.hofstra.edu/geotrans/eng/methods/ch3m3en.html

[10]. Carolina Grünschloß (2005). The Development of International Airports into Air Cargo Hubs and its Economic Impacts on Local Structures. Faculty of Business of Business Administration and Management, Heinrich-Heine University, Dusseldorf.

[11]. Gambiye, A. (2010). An Assessment of Ticketing and Reservation Operations of IRS Airline in Yola. An Unpublished Diploma Research Study at the Nigerian Institute of Transport Technology (NITT), Zaria.

[12]. Gardiner, J; Ison, S and Humpreys I (2005). Factors Influencing Cargo Airlines' Choice of Airport: An International Survey. Journal of air Transport Management vol.11, $393-399$.

[13]. Graham, A. (2001). Managing Airports: An International Perspective. Butterworth-Heinemann, Oxford.

[14]. Hsu, C. Yang, L. Lian, P. and Chen, Y. (2005). High Tech Firms Perception and Demand for Air Cargo Logistics Services. Journal of the Eastern Asia Society for Transportation Studies Vol 6, pp 2868-2880.

[15]. Hui, G. W. L. Hui, Y.V and Zhang, A (2004). Analysing China's Air Cargo Flows and Data. Journal of Air Transport Management Vol 10, $125-135$.

[16]. Idrisu I.D. (2004). The Commercial \& Regulatory Implications for Air Transport Liberalization \& Open Skies Agreement in Nigeria. Ph.D Thesis St. Clemens University, Turks \& Carcos Island, British West Indies.

[17]. Jiang, H; Liling, R. and Hansman, J.R (2006). Market and Infrastructure Analysis of Future Air Cargo Demand in China. Department of Aeronautics and Astronautics, Massachusetts Institute of Technology, Cambridge, MA 02139.

[18]. Kasarda, J.D and Green, J. (2004). Air cargo: Engine for Economic Development. Kenan Institute of Private Enterprise, KenanFlagler Business School, University of North Carolina, Chapel Hill, NC27599 - 3440, USA.

[19]. Kasarda, J.D and Sullivan, D.L (2005). Air cargo, Liberalisation and Economic Development. Kenan Institute of Private Enterprise, Kenan-Flagler Business School, University of North Carolina, Chapel Hill, NC27599 - 3440, USA.

[20]. Kasarda, J.D and Sullivan, D.L (2006). Air cargo, Liberalisation and Economic Development. Annals of Air and Space Law, McGill University, Montreal.

[21]. Karsarda, J.D; Stephen, J.A and Makoto, M. (2006). The impact of Air Cargo Industry on the Global Economy. Centre for Air Commerce Kenan Institute of Private Enterprise, Kenan-Flagler Business School, University of North Carolina, Chapel Hill, USA.Paper prepared for The International Air Cargo Association, Air Cargo Forum, Calgary, Canada.

[22]. Oladele S.F. (2005). African Air Transport in the 21st Century. A Case Study of the Contrasting Experience of Nigeria and Kenya. An M.Sc Thesis at the Cranfield University.

[23]. Olateru, A. (2005). The Economic Importance of Cargo Business to the Nigerian Economy. Paper Delivered presented at the First Yearly Cargo Conference organized by Aviation Review, Lagos.

[24]. Omoloye, R. (1996). Call to Organise Nigerian Air Transportation for the 21st Century. presentation at a seminar titled, Preparing Nigerian Air Transportation for the $21^{\text {st }}$ Century, November 28, 1996, Lagos. 
[25]. NAHCo (2006 - 2011). Nigerian Aviation Handling Company Plc. Annual Reports and Accounts.

[26]. Yahaya, D.B. (2005). Airports Capacity Utilisation in Nigeria. An unpublished MTL Research study at the Nigerian Institute of Transport Technology (NITT), Zaria.

[27]. Yamane, T (1967). Statistics; An Introductory Analysis. 2nd Edition, Published by Harper and Row, New York.

[28]. Zhang, A. (2003). Analysis of International Air Cargo Hub: the Case of Hong Kong. Journal of Air Transport Management 9 (2003) $123-138$.

[29]. Zhang, A and Zhang, Y., (2002). Issues on Liberalisation of Air Cargo Services in International Aviation. Journal of Air Transport Management Vol. 8, 275-287. 